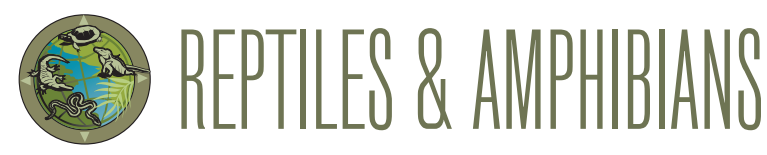

\title{
A Preginant Common Lancehead, Bothrops atrox (Viperidae), from the Northern Andes of Colombia
}

\author{
Julián A. Rojas-Morales ${ }^{1}$, Juan Felipe León-León ${ }^{2}$, and Héctor E. Ramírez-Chaves ${ }^{1,3}$ \\ ${ }^{1}$ Natural History Laboratory, Integrative Zoological Biodiversity Discovery, Centro de Museos, Museo de Historia Natural, Universidad de Caldas, \\ Manizales, Caldas, 170004, Colombia (julian.herpetologia@gmail.com) \\ ${ }^{2}$ Programa de Biología, Facultad de Ciencias Exactas y Naturales, Universidad de Caldas, Manizales, Caldas, 170004, Colombia (juanfelipeleon2@gmail.com) \\ ${ }^{3}$ Departamento de Ciencias Biológicas, Facultad de Ciencias Exactas y Naturales, and Centro de Museos, Museo de Historia Natural, Universidad de Caldas, \\ Manizales, Caldas, Colombia (hector.ramirez@ucaldas.edu.co)
}

$\mathrm{R}^{\mathrm{e}}$ eproduction (from mating to hatching) of Neotropical pitvipers in the genus Bothrops has received more attention in recent decades (e.g., Almeida-Santos and Salomão 2002; Marques et al. 2013; Silva et al. 2019). The Common Lancehead, Bothrops atrox (Linnaeus 1758) is a medium-sized (total length 750-1,250 mm), mainly nocturnal snake with a generalist diet; it is distributed throughout the Amazon and Orinoco Basins in northern South America, with records from the eastern slopes of the Cordillera Oriental of the Andes of Colombia to an elevation of 1,900 m asl (Dunn 1944; Martins and Oliveira 1998; Campbell and Lamar 2004; Wallach et al. 2014; Nogueira et al. 2019). According to Campbell and Lamar (2004), snakes from elevations exceeding 1,500 $\mathrm{m}$ asl on the eastern slopes of the Cordillera Oriental of Colombia belong to a distinct species, but they are currently included in $B$. atrox pending an integrative taxonomic review including low- and mid-elevation samples for comparison. An extended reproductive cycle for $B$. atrox in the Brazilian Amazon was described by Silva et al. (2019), with pregnant females occurring throughout the year (except May) and an average litter size of 11 (range 3-32) neonates that increases with female body size. Seasonal births, however, were found to occur mainly at the end of the dry season (August-October) (Silva et al. 2019).

Despite extensive knowledge of $B$. atrox reproduction in Brazil and the Amazon Basin (Dixon and Soini 1977; Duellman 1978; Martins and Oliveira 1998; Silva et al. 2019), we know little about reproduction in populations from Colombia and other countries with Andean populations (Quiñones-Betancourt et al. 2018). Herein we present a record of a pregnant female from an Andean mid-elevation locality in the Cordillera Oriental of Colombia.

An adult female $B$. atrox (SVL $787 \mathrm{~mm}$; tail length $129 \mathrm{~mm}$ ) (Fig. 1) killed by locals on 20 October 2020 at the Vereda Algodones, Municipality of Ubalá, Department of Cundinamarca, Colombia $\left(04.6967^{\circ} \mathrm{N},-73.3699^{\circ} \mathrm{W}\right.$, WGS84; elev. 1,287 $\mathrm{m}$ asl) was deposited in the Museo de Historia Natural of the Universidad de Caldas (MHN-UCa R-0619), Manizales, Colombia. General pholidosis of the snake includes 25-23-19 dorsal scales, 190 ventrals, undivided cloacal plate, and 54 divided subcaudal scales. Although the shattered head prevented a count of cephalic scales, the specimen had a color pattern and pholidosis similar to B. atrox sensu stricto. The snake contained 14 oviductal eggs averaging $24.12 \pm 1.89 \mathrm{~mm}(21.00-28.41 \mathrm{~mm} ; \mathrm{n}=12)$ in length and

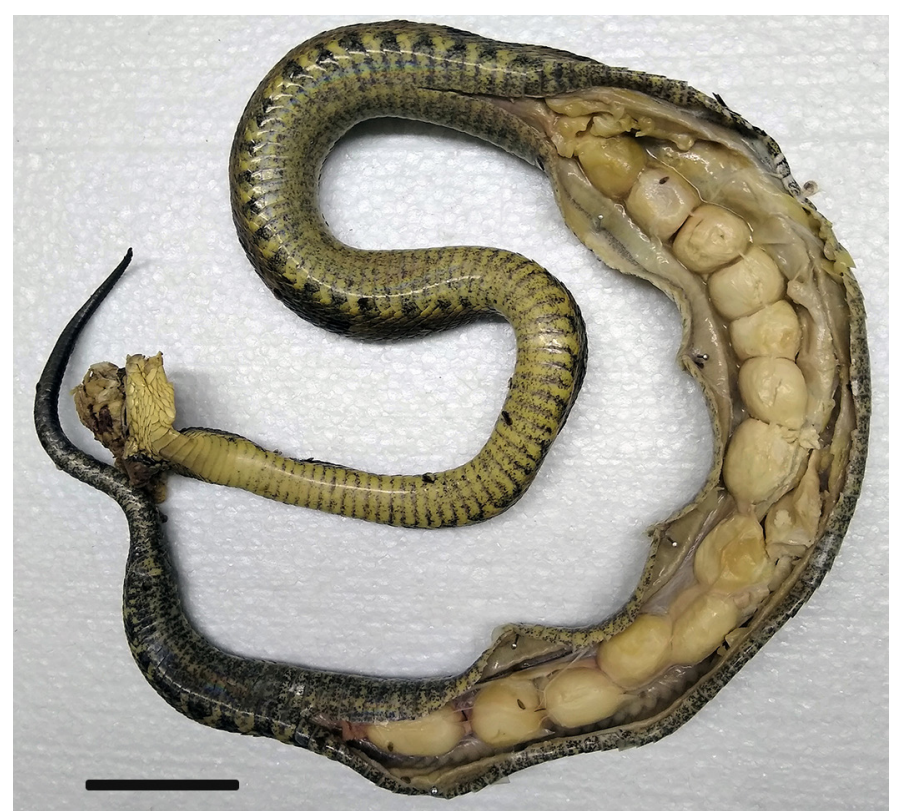

Fig. 1. A female Common Lancehead (Bothrops atrox) (MHN-UCa R-0619; SVL $787 \mathrm{~mm}$, TL $129 \mathrm{~mm}$ ) from Ubalá, Department of Cundinamarca, Colombia, with 14 oviductal eggs. Scale bar $=5 \mathrm{~cm}$. Photograph by Héctor E. Ramírez-Chaves. 
$22.24 \pm 2.88 \mathrm{~mm}(15.80-25.12 \mathrm{~mm} ; \mathrm{n}=12)$ in width. We found no primary or secondary follicles on the ovaries (see Almeida et al. 2014 for descriptions and definitions). We dissected the three largest eggs and found no evidence of embryo or yolk formation, suggesting recently ovulated eggs. After dissection, we sutured the specimen following the protocol of Hoyos et al. (2015).

For B. atrox in the Amazon Basin, the female reproductive cycle (i.e., ovulation-fertilization-pregnancy) is continuous throughout the year in synch with the relatively constant environmental conditions (Silva et al. 2019). However, whether this pattern will hold for higher-elevation populations inhabiting areas where precipitation is bimodal (MarchMay and September-December) remains unknown.

\section{Acknowledgments}

We are deeply indebted to Henrique Braz for helpful comments on this note.

\section{Literature Cited}

Almeida-Santos, S.M. and M.G. Salomão. 2002. Reproduction in Neotropical pitvipers, with emphasis on species of the genus Bothrops, pp. 445-462. In: G.W Schuett., M. Hoggren, M.E. Douglas, and H.W. Greene (eds.), Biology of the Vipers. Eagle Mountain Publishing, Eagle Mountain, Utah, USA.

Almeida-Santos, S.M. H.B. Braz, L.C. Santos. L.R. Sueiro. V.A. Barros. C.A. Rojas, and K.N. Kasperoviczus. 2014. Biologia reprodutiva de serpentes: recomendações para a coleta e análise de dados. Herpetologia Brasileira 3: 14-24.

Campbell, J.A. and W.W. Lamar. 2004. The Venomous Reptiles of the Western Hemisphere. Volume I. Comstock Publishing Associates, Cornell University Press, Ithaca, New York, USA.
Dixon, J.R. and P. Soini. 1977. The Reptiles of the Upper Amazon Basin, Iquitos Region, Peru. II. Crocodilians, Turtles and Snakes. Contributions in Biology and Geology Number 12. Milwaukee Public Museum, Milwaukee, Wisconsin, USA.

Duellman, W.E. 1978. The biology of an equatorial herpetofauna in Amazonian Ecuador. Miscellaneous Publication. Museum of Natural History, University of Kansas 65: 1-352.

Dunn, E.R. 1944. Los géneros de anfibios y reptiles de Colombia. Tercera parte: reptiles, orden de las serpientes. Caldasia 3: 155-224.

Hoyos, M.A., S.M. Almeida-Santos, and C.A. Rojas. 2015. A suture method to optimize the condition of snake specimens in herpetological collections. Herpetological Review 46: 27-29.

Martins, M.M. and M.E. Oliveira. 1998. Natural history of snakes in forests of the Manaus region, central Amazonia, Brazil. Herpetological Natural History 6: 78-150.

Marques, O.A.V., K. Kasperoviczus, and S.M. Almeida-Santos. 2013. Reproductive ecology of the threatened pitviper Bothrops insularis from Queimada Grande Island, Southeast Brazil. Journal of Herpetology 3: 393-399. https://doi. org/10.1670/11-267.

Nogueira, C.C., A.J.S. Argôlo, V. Arzamendia, J.A. Azevedo, F.E. Barbo, R.S. Bérnils, B.E. Bolochio, M. Borges-Martins, M. Brasil-Godinho, H. Braz, M.A. Buononato, D.F. Cisneros-Heredia, G.R. Colli, H.C. Costa, F.L. Franco, A. Giraudo, R.C. Gonzalez, T. Guedes, M.S. Hoogmoed, O.A.V. Marques, G.G. Montingelli, P. Passos, A.L.C. Prudente, G.A. Rivas, P.M. Sanchez, F.C. Serrano, N.J. Silva, C. Strüssmann, J.P.S. Vieira-Alencar, H. Zaher, R.J. Sawaya, and M. Martins. 2019. Atlas of Brazilian snakes: verified point-locality maps to mitigate the Wallacean shortfall in a megadiverse snake fauna. South American Journal of Herpetology 14: 1-274. https://doi. org/10.2994/SAJH-D-19-00120.1.

Silva, K.M.P., K.B. Silva, L.R. Sueiro, M.E.S. Oliveira, and S.M. AlmeidaSantos. 2019. Reproductive biology of Bothrops atrox (Serpentes, Viperidae, Crotalinae) from the Brazilian Amazon. Herpetologica 75:198-207. https:// doi.org/10.1655/D-18-00023.

Quiñones-Betancourt, E., J.C. Díaz-Ricaurte, T. Angarita-Sierra, E.C. GuevaraMolina, and R.D. Díaz-Morales. 2018. Bothrops atrox (Linnaeus, 1758). Catálogo de Anfibios y Reptiles de Colombia 4: 7-23.

Wallach, V., K.L. Williams, and J. Boundy, J. 2014. Snakes of the World: A Catalogue of Living and Extinct Species. Taylor and Francis, CRC Press. 1237 pp. 